\title{
Case report: notalgia paresthetica
}

\begin{abstract}
Notalgia paresthetica is a neuropathic pain characterised with hyperpigmentated skin lesion, itch and numbness in scapular region. We summerise three cases with notalgia parestetica and their treatment.
\end{abstract}

Keywords: notalgia paresthetica, neuropathic pain, hyperpigmentated skin lesion, scapular region, etiology
Volume 4 Issue 5 - 2019

Seide Karasel,' Dua Cebeci, ${ }^{2}$ Suzan Yalinkaya ${ }^{3}$ 'Departmnet of Physical Medicine and Rehabilitation, Famagusta State Hospital, Cyprus

${ }^{2}$ Departmnet of Dermatology, Famagusta State Hospital, Cyprus

${ }^{3}$ Departmnet of Neurology, Private Yasam Hospital, Cyprus

Correspondence: Seide Karasel, Department of Physical Medicine and Rehabilitation, Famagusta State Hospital, Famagusta, Cyprus, Tel 05338707533,

Email karaselseide@yahoo.com

Received:September II, 2019 | Published: September 16, 2019

\section{Introduction}

Notalgia paresthetica is a neuropathy of the dorsal branches of T2-T6 with unknown etiology and characterized by flammable pain in the scapular region, paresthesias, hyperesthesia and pruritic hyper pigmented skin lesion accompanied by tenderness. Although the etiology is unknown; posterior spinal nerve entrapment, chronic nerve trauma, increased dermal innervation, viscereocutaneous reflex mechanisms, activation of neurotoxic mediators. It is a chronic clinical disease characterized by pain, pruritus and hyper pigmented nonspecific skin lesions in the dorsal vertebral and scapular area. There is no information about its incidence and etiology in the literature. ${ }^{2}$ We summerize three case with notalgia parestetica and their treatment.

\section{Case I}

A 62-year-old female patient presented with complaints of neck, back pain, burning in the back, pruritus. Physical examination revealed a hyper pigmented skin lesion of approximately $4 \times 4 \mathrm{~cm}$ diameter on the lateral side of the left scapula. On the left there were tight bands in the middle fibers of the trapezius muscle. Cervical joint range of motion was within normal limits and lateral rotations were painful. Hypoesthesia and dorsal pare vertebral muscle spasm were present in the dorsal region. Laboratory tests were normal Degenerative changes were detected in the cervical and dorsal radiographic examinations. There was no protruding disc in the C6-7 MRI. There was no compression of the spinal nerve. No abnormal findings were observed in needle EMG. The skin lesion was consulted by the dermatology clinic and the diagnosis of NP was confirmed by differential diagnosis. Pregabalin treatment was started with $75 \mathrm{mg} /$ day and gradually increased. 10 sessions of ultrasound $(1 \mathrm{w} 7 \mathrm{~cm} 2)$, infrared, TENS (stimulation intensity 20 microamps, $100 \mathrm{~Hz}$, duration of session $20 \mathrm{~min}$ ) and isometric, range of motion and strengthening exercises were given to the cervical and dorsal vertebral regions for 10 days. Significant improvement was achieved in the patient's clinic in the first month of treatment.

\section{Case 2}

A 45-year-old female patient presented to the dermatology outpatient clinic with complaints of burning and pruritus on her back, and was referred to the physical therapy outpatient clinic with a preliminary diagnosis of notalgia paresthetica. The patient stated that she had complaints for 2 years. Physical therapy, but little benefit. A $6 \times 8 \mathrm{~cm}$ hyper pigmented macular skin lesion was detected in the medial right scapula. Examination; In the evaluation of joint range of motion (ROM), neck flexion and extension were open and painless, right and left rotations were open, and end of ROM was painful. Painful fibrous bands were detected in many dorsal muscles, especially in the trapezius muscles during palpation. Sensory examination revealed hypoesthesia and paresthesia in the center of the skin lesion. There was degeneration on cervical vertebra radiographs. Pregabalin $75 \mathrm{mg}$ / day was started and the dose was gradually increased. Trigger points in trapezium muscles were treated with dry needling ( 5 sessions at 3-day intervals) Stretching the back and neck muscles and isometric exercises were given. Patient's clinic was significant better in the first month control.

\section{Case 3}

A 28-year-old female patient presented with a complaint of burning on her back. A $3 \times 5 \mathrm{~cm}$ hyper pigmented macular skin lesion was detected in the medial right scapula. In physical examination; posterior defect (head ante flexion, shoulders protraction, increased dorsal kyphosis). Joint range of motion (ROM) evaluation, neck flexion and extension open and painless, right and left rotations were open. Sensory examination revealed hypoesthesia and paresthesia in the center of the skin lesion. There was a significant decrease in lordosis in the cervical radiography and an increase in the kyphosis in the thoracic cavity. The patient was given 15 sessions of ultrasound $(1 \mathrm{w} 7 \mathrm{~cm} 2)$, infrared, TENS (stimulation intensity 20 microamps, 100 $\mathrm{Hz}$, duration of session $20 \mathrm{~min}$ ) and isometric, range of motion and strengthening exercises. Significant improvement was achieved in the patient's clinic in the first month of Treatment (Figure 1) 


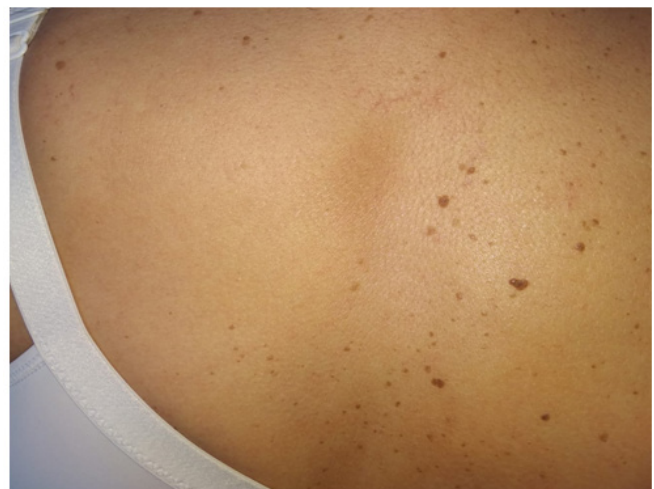

Figure I A 32-year-old female patient presented with a complaint of pain on his back and itching.

\section{Discussion}

Notalgia paresthetica is related with spinal nerve compression, degenerative changes in the spine, paraspinal muscle spasm or fibrous bands may be associated with, $60 \%$ of patients in the cervical and thoracic radiographs support the contribution of spinal nerve trauma to the pathogenesis. ${ }^{3,4}$ The opinion of dermatology is important in these patients; dermatological diseases such as atopic dermatitis, post inflammatory hyper pigmentation and prurigo nodular is should be kept in mind in the differential diagnosis. ${ }^{4}$ Electromyographic findings are variable in these cases. Denervation potentials can be seen in the paraspinal muscles as well as normal in our patients. ${ }^{5,6}$ Topical aesthetics, topical capsaicin, topical antihistaminic, intra-lesion corticosteroid and botulinum toxin are the preferred local therapies for the treatment of notalgia paresthetica. ${ }^{7}$ Gabapentin, pregabalin, oxcarbazepine, amitriptyline, paravertebral local anesthetic block, spinal manipulation and physical therapy applications, neck and back muscles stretching and strengthening exercises are other treatment options..$^{8-13}$ The patients who underwent kinesiologic taping also had good results. ${ }^{14}$ As a result; Multidisciplinary approach is important in notalgia paresthetica. Especially in the branches dealing with musculoskeletal system such as physical medicine and rehabilitation, orthopaedics, neurosurgery, skin findings in the scapular region and accompanying paresthetic complaints, consideration of notalgia paresthetica diagnosis should be taken into consideration and treatment programs according to the symptoms of the patient, medical therapy, physical therapy agents, trigger point injections and exercises should be a versatile treatment

\section{Funding details}

There was no funding for this study.

\section{Acknowledgement}

None.

\section{Conflict of interest}

The authors declare that there is no conflict of interest.

\section{References}

1. Raison-Peyron N, Meunier L, Acevedo M, et al. Notalgia paresthetica: Clinical, physiopathological and therapeuticaspects. A study of 12 cases. J Eur Acad Dermatol Venereol. 1999;12:215-221.

2. Wang CK, Gowda A, Barad M, et al. Serratus muscle stimulation effectively treats notalgia paresthetica caused by long thoracic nerve dysfunction: a case series. J Brachial Plex Peripher Nerve Inj. 2009;22:4 17 .

3. Ellis C. Notalgia paresthetica: the unreachable itch. Dermatol Pract Concept. 2012;3:2.

4. Savk O, Savk E. Investigation of spinal pathology in notalgia paresthetica J Am Acad Dermatol. 2005;52:1085-1087.

5. Marcusson JA, Lundh B, Sidén A, et al. Notalgia paresthetica--puzzling posterior pigmented pruritic patch. Report on two cases. Acta Derm Venereol. 1990;70:452-454.

6. Massey EW, Pleet AB. Electromyographic evaluation of notalgia paresthetica. Neurology. 1981;31:642.

7. Pérez-Pérez LC. General features and treatment of notalgia paresthetica. Skinmed. 2011;9:353-939.

8. Wallengren J, Klinker M. Successful treatment of notalgia paresthetica with topical capsaicin: vehicle-controlled, double-blind, crossover study. J Am Acad Dermatol. 1995;32:287-289.

9. Loosemore MP, Bordeaux JS, Bernhard JD. Gabapentin treatment for notalgia paresthetica, a common isolated peripheral sensory neuropathy. $J$ Eur Acad Dermatol Venereol. 2007;21:1440-1441.

10. Savk E, Bolukbasi O, Akyol A, et al. Open pilot study on oxcarbazepine for the treatment of notalgia paresthetica. $J$ Am Acad Dermatol. 2001;45:630-632.

11. Weinfeld P. Successful treatment of notalgia paresthetica with botulinum toxin type A. Arch Dermatol. 2007;14:980-982.

12. Savk E, Savk O, Sendur F. Transcutaneous electrical nerve stimulation offers partial relief in notalgia paresthetica patients with a relevant spinal pathology. J Dermatol. 2007;34:315-319.

13. Anne B. Fleischer, Tammy J. et al. Fleischer; notalgia paresthetica: successful treatment with exercises. Acta Dermato-Venereologica. 2010;29:9.

14. Subası V, Cakır T, Atasoy MF. Efficacy of dry needling and kinesiotaping combination in the treatment of notalgia paresthetica: a case report. Turk J Phys Med Rehab. 2016;62(3):273-276. 